\title{
Development of PET bottle shredder reverse vending machine
}

\author{
Noor Hasyimah Abu Rahim ${ }^{1 *}$ and Ahmad Nor Haziq Muhammad Khatib ${ }^{2}$ \\ Lecturer, UniKL Robotics and Industrial Automation Center (URIAC), Industrial Automation Section, Universiti \\ Kuala Lumpur Malaysia France Institute, Selangor, Malaysia ${ }^{1}$ \\ Undergraduate, Bachelor of Engineering Technology in Mechatronics, Universiti Kuala Lumpur Malaysia France \\ Institute, Selangor, Malaysia ${ }^{2}$
}

Received: 19-September-2020; Revised: 10-January-2021; Accepted: 20-January-2021

(C)2021 Noor Hasyimah Abu Rahim and Ahmad Nor Haziq Muhammad Khatib. This is an open access article distributed under the Creative Commons Attribution (CC BY) License, which permits unrestricted use, distribution, and reproduction in any medium, provided the original work is properly cited.

\begin{abstract}
This paper presents the development of a reverse vending machine (RVM) with shredding features that can shred the polyethylene terephthalate (PET) bottles. Plastic waste such as plastic bottles and plastic containers are often being thrown into landfills. Dustbins are overflowed due to these used bottles occupied very large space. Used plastic bags and plastic bottles in different sizes are found scattered in the streets, gutters, and even in drains causes a significant environmental threat. A reverse vending machine is a machine that accepts empty beverage containers and returns money where it helps to encourage user to recycle. The returned PET bottles are shredded into smaller pieces for the use of next recycling process. The hardware is equipped with capacitive sensors that will detect bottles, status display by using Liquid Crystal Display (LCD) and all major process will be controlled by Arduino UNO. The microcontroller will send the signal to activate both motors which are (direct current) DC motors that will actuate the shredding process and coin dispensing respectively. This PET shredder RVM is capable to shred the standard size of empty PET bottles and consumers will be rewarded with amount according to number of bottles inserted. Since it is in a form of vending machine, it is suitable to be placed near the streets, buildings and convenience stores. Positively, the project can benefit the consumers in a way that they do not have to go to recycle centre to recycle PET bottles to the shredded form of plastic.
\end{abstract}

\section{Keywords}

Reverse vending machine, Plastic shredding, Recycle.

\section{Introduction}

Recycling is the process of treating waste materials to produce new products. Recycling significantly will lower the amount of waste, the use of new raw materials, energy consumption, air pollution that coming from waste combustion and water pollution when leachate bringing all the contaminants from landfill [1]. Malaysians are producing waste products at a frightening rate compared to the natural degradation process. The resources are being used at a very high speed exceeding the rate of these materials are being reproduced. The recorded recycling rate in Malaysia is only 10.5 per cent, which is far behind the developed countries [2].

By 2020, Malaysia has targeted to not only achieve the $22 \%$ recycling rate, but also tremendous improvement in becoming a zero waste nation.

*Author for correspondence
To achieve this, continuous commitment and support from the government, private sector, and public are very important [3]. This paper presents the project that combines the concept of RVM and plastic shredder machine where it can turn the original form of PET bottle into shredded plastic which had minimized one recycling process in the recycle center. The objective of this project is mainly to:

- Shred the inserted PET bottles

- Reward the user in form of money in exchange to the returned PET bottles

- Help collect recyclable materials and hence, to boost recycling activities anywhere anytime

The scope covers the development of the RVM's prototype until the performance evaluation including functionality and reliability testing. The remainder of the paper is organized as follows. Section 2 briefs the work done by others. Material and methods from hardware development until assembly is described in Section 3. In Section 4, result from this proof of 
concept work is presented, followed by discussion in Section 5. This paper ends with conclusion and the proposition of future works.

\section{Literature review}

Polyethylene terephthalate, commonly abbreviated PET, PETE, is a thermoplastic polymer resin of the polyester family and is used in synthetic fibers. PET bottles are commonly used by the manufacturers as containers for their drinks, for example, carbonated beverages, water bottles and many food products. Beside glass and paper, most of the packaging materials like bottles and containers that used to keep food products and other consumer goods as well are using PET as raw material. The range cover from beverages bottles, food jar, edible oils, detergents and cosmetics, also pharmaceutical products.

Plastic bottle takes time to be decomposed because plastic is non-biodegradable. Therefore, it is essential that plastic should be recycled. The process of recycling starts with collecting plastic bottles. Then, they must be sorted in different categories. In order to form a pallet, the component must be crushed or melted. Therefore, the plastic bottle must be cut into smaller pieces appropriate with the machine condition before transferred to the further process, such as injection molding [4]. Impact system and rotary system are two common system used in the crushing machine.

In other countries such as Norway and Japan, they already introduced the RVM and it was a huge success. For example, TOMRA Japan has placed around 1200 RVM in Japan and the machines collected 300 million PET bottles to be recycled in a year as stated in [5]. The RVM is placed at accessible area such as in front of convenience store to allow consumer to return empty PET containers for recycling purpose. The machine then will reward the end user in form of cash or credit point where it helps to encourage user to recycle and time saving. While in Malaysia, RVM is still in the process to be introduced and installed across the country.

Previous related research regarding RVM and shredding machine presented in [6-15] shows the variety design of cutter used to crush the plastic bottles, different type of controller depending on the complexity of the machine and mechanism of money dispensing like the one implemented in vending machine. Discrete sensors are commonly used to detect and recognize the plastic bottle before the next process can be proceeded and to avoid the different recycle material from mixing up.

In the paper by Deena Mariya [16], image processing system is used to identify the inserted plastic bottle is a real plastic or not and the point will be calculated and credited correspondingly. It involved three main steps which are making of dataset, model training and inference. Sinaga in [17] proposed the use of barcode scan system for the operation of RVM where it can help to sort out between plastic bottles and cans by comparing the barcode line with developed database.

In most of shredder machine, pulley mechanism is used which is powered through the belt drive to reduce the speed of the shaft and enable the shredder to shred the plastic bottles completely. The jaw couplings on the other hand are designed to be able to transfer large amounts of torque, as the application of shredding is required. The design of cutting tool and number of shaft contributes to the amount and quality of shredded plastic after certain period of time. All machine offers one function only which is plastic shredding without the function of RVM.

\section{Methods}

3.1Framework and product design

In mechanical design point of view, the RVM consist of several sub systems, material, dimension, and the related important aspects. Figure 1 shows the 3D model of PET bottle shredder RVM. It is designed in square shaped, divided into three main sub systems; Collecting, Shredding and Coin Dispensing. It is installed with 1-unit LCD 16x2 display, 1 shredder unit, 1-coin dispenser unit, 2 unit capacitive sensors, 1 unit 5V DC motor, 1 unit $24 \mathrm{~V}$ DC motor with motor driver MD10-POT, 1-unit chain drive with sprockets, $124 \mathrm{~V}$ power supply unit, 3 LED lights and 1 Arduino Uno R3 controller. The hopper is equipped with capacitive sensor to detect and count the quantity of empty bottles. Each bottle will be shredded inside the shredder unit that is located at the bottom of the machine. Coin is dispensed out through dispensing unit. In order to run the RVM, a flowchart was design and the program was developed using Arduino IDE software. According to system flowchart in Figure 2, the system starts by inserting plastic bottles and the capacitive sensor will detect the presence of the bottles. The Arduino will make the decision to turn on the shredder motor and undergo shredding process. Along the shredding process, the coin dispenser motor will turn on to push the coin out once the capacitive sensor reaches the counting number of four bottles. 
Noor Hasyimah Abu Rahim and Ahmad Nor Haziq Muhammad Khatib

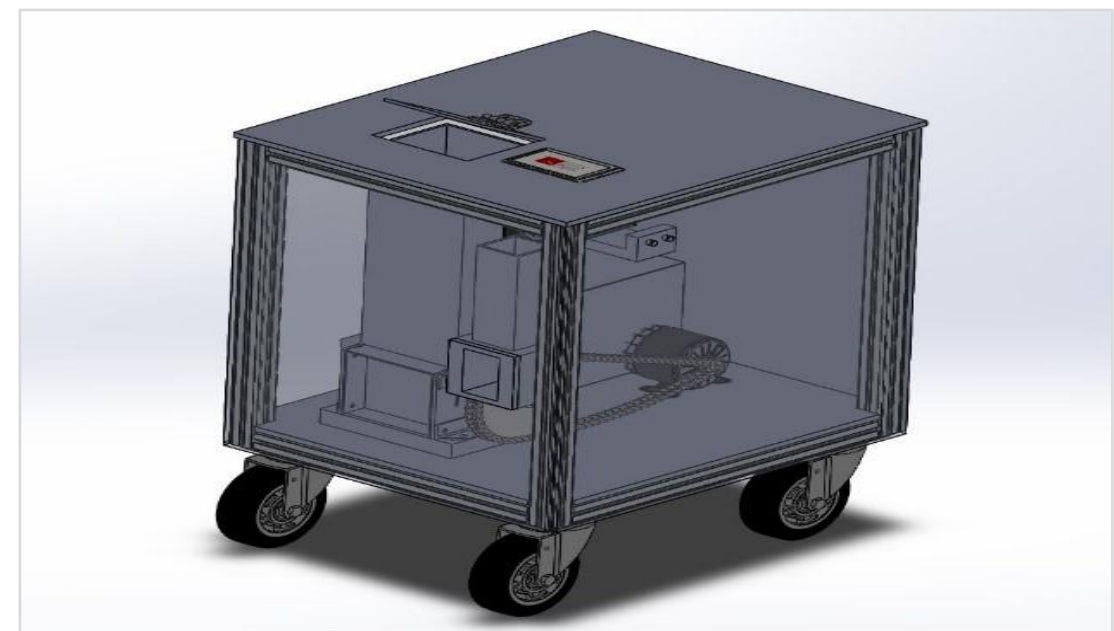

Figure 1 Main frame mechanical design of PET bottle shredder reverse vending machine

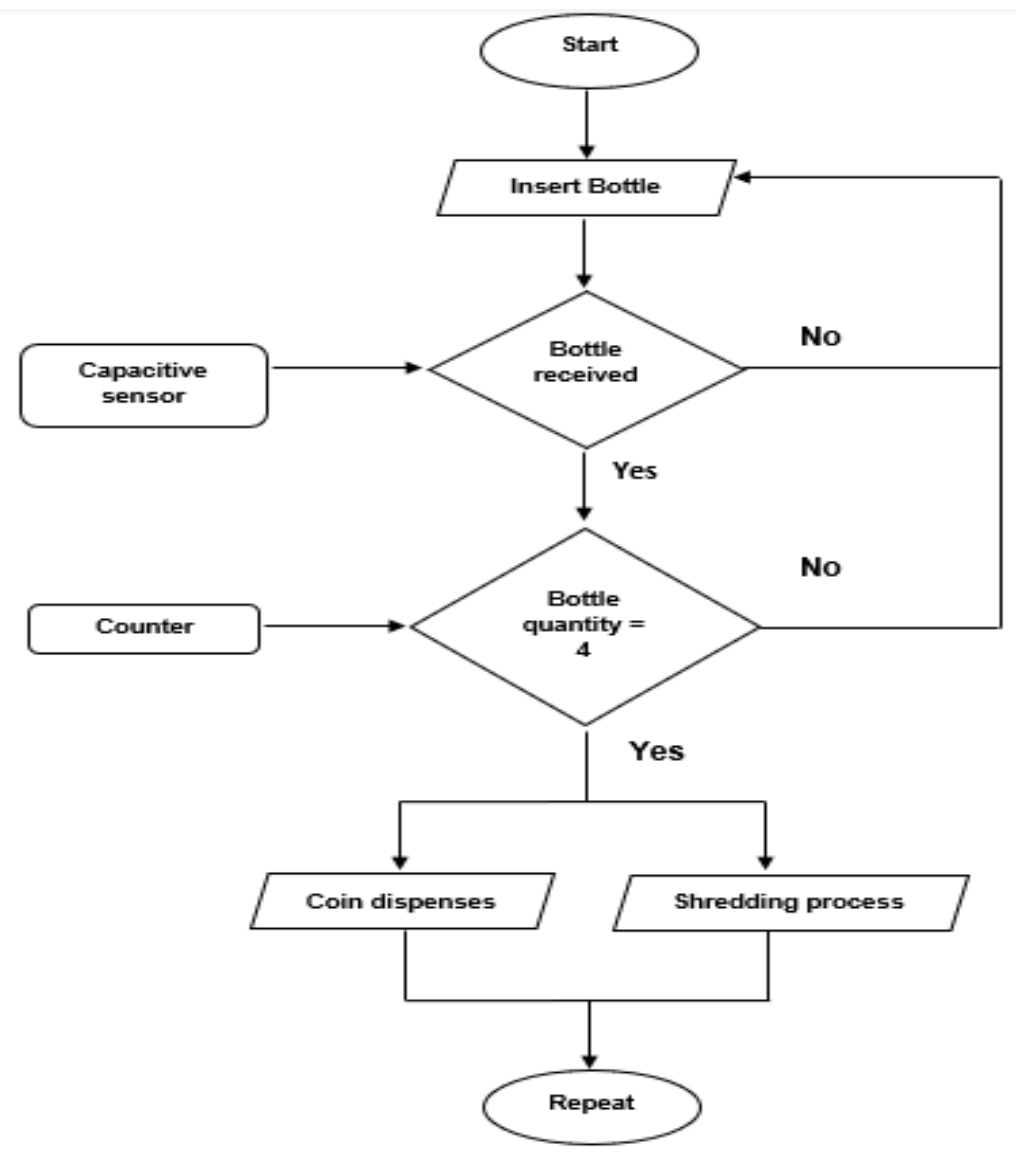

Figure 2 System flowchart

\subsection{Hardware components}

\section{A. Capacitive proximity sensor}

This capacitive proximity sensor is used to detect plastic bottles that go through the reverse vending machine. It uses the variation of Capacitance value between object and sensor. Capacitive proximity sensor output is typically transmitted as a contact closure or a pulse that is activated when an object reaches a specific distance threshold. 


\section{B. Shredder unit}

The purpose of the shredding mechanism is to shred up to four plastic bottles at a time. The size of the shredder is $210 \mathrm{~mm} \times 149 \mathrm{~mm} \times 135 \mathrm{~mm}$. It has 14 curve edge cam shaped cutting knives that are arranged in a "V" shaped design as shown in Figure 3 . The shaft is hexagon shaped and made of stainless steel. The knives are assembled to the single shaft with spacer in between them. The material of the cutting knives is made from mild steel while the body of the shredder case is made from steel.

\section{Chain drive}

The chain drive is a way of transmitting mechanical power form one place to another. Power convey by a roller chain known as drive chain or transmission chain. The drive gear pulls the chain with mechanical force into system and transfer to another with same or different output power. In this project, chain drive is used to transfer energy motion from DC motor to shredder.

\section{D.Sprocket}

Sprocket is a profiled wheel with teeth that mesh to chain, track, and other indented material. Sprocket transmit rotary motion between a motor and a shredder. In this project, 12 teeth with $15 \mathrm{~mm}$ diameter use to transfer motion to 48 teeth with $75 \mathrm{~mm}$ diameter. This motion transfer is use for the motor to drive the shredder unit.

\section{E. Arduino uno R3}

Arduino Uno R3 is a widely used microcontroller board that is designed based on ATmega328P. It offers It is a microcontroller board based on ATmega328P. It has 14 digital input/output pins, 6 analog inputs, a $16 \mathrm{MHz}$ quartz crystal, a USB connection, a power jack, an ICSP header and a reset button. It provides enough input and output to support the PET bottle shredder Reverse Vending Machine system development.

\section{F. Coin dispenser unit}

The coin dispenser unit is developed to dispense RM0.20 coin for every 4 bottles counted. It uses a $12 \mathrm{~V}$ DC motor with $30 \mathrm{rpm}$ that rotates the spring to dispense coin. The size of the coin dispenser is $70 \mathrm{~mm}$ $\mathrm{x} 160 \mathrm{~mm} \times 62 \mathrm{~mm}$. The coins are stored in a spring inside a covered box with thickness of $2 \mathrm{~mm}$.

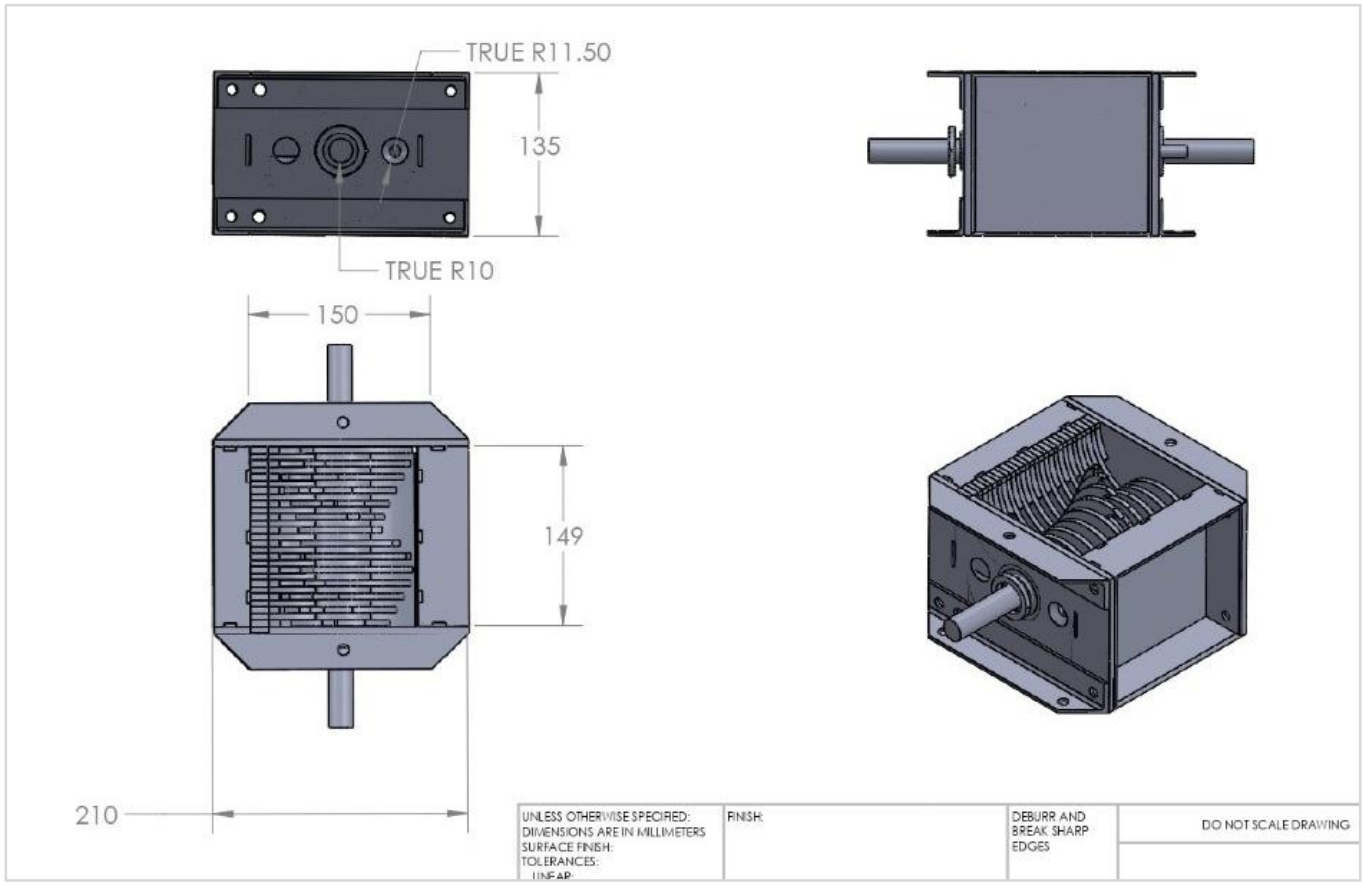

Figure 3 The design of shredder unit

\subsection{Circuit and component construction}

This system uses one controller that is Arduino Uno R3. There is one LCD $16 \times 2$ module, three LED light, one 5V Dc motor with motor driver (L293D) and one capacitive sensor used for this system. All the wire connection from the controller to each component is shown in the Figure 4 below. For the component's placement, all the electronic components are soldered on a donut board. Power supply unit $24 \mathrm{~V} 10 \mathrm{amp}$ is being used to supply power to the Arduino Uno R3 
and motor driver to drive $24 \mathrm{~V}$ Dc electrical scooter motor. The power supply unit is stored inside an electrical box as well. The box is then placed at the base behind the shredder unit. For the shredder unit, it is placed at the base and tighten with 4 bolts and nuts to keep the shredder from moving. There is a hopper that is made from plywood and attached on top of the shredder. The shaft of the shredder is attached with a 48 teeth sprocket. The shredder is driven by a chain attached to the $24 \mathrm{~V}$ Dc motor. The motor is attached to an $\mathrm{L}$ bracket mounting and the distance between the shredder and the motor is $350 \mathrm{~mm}$.

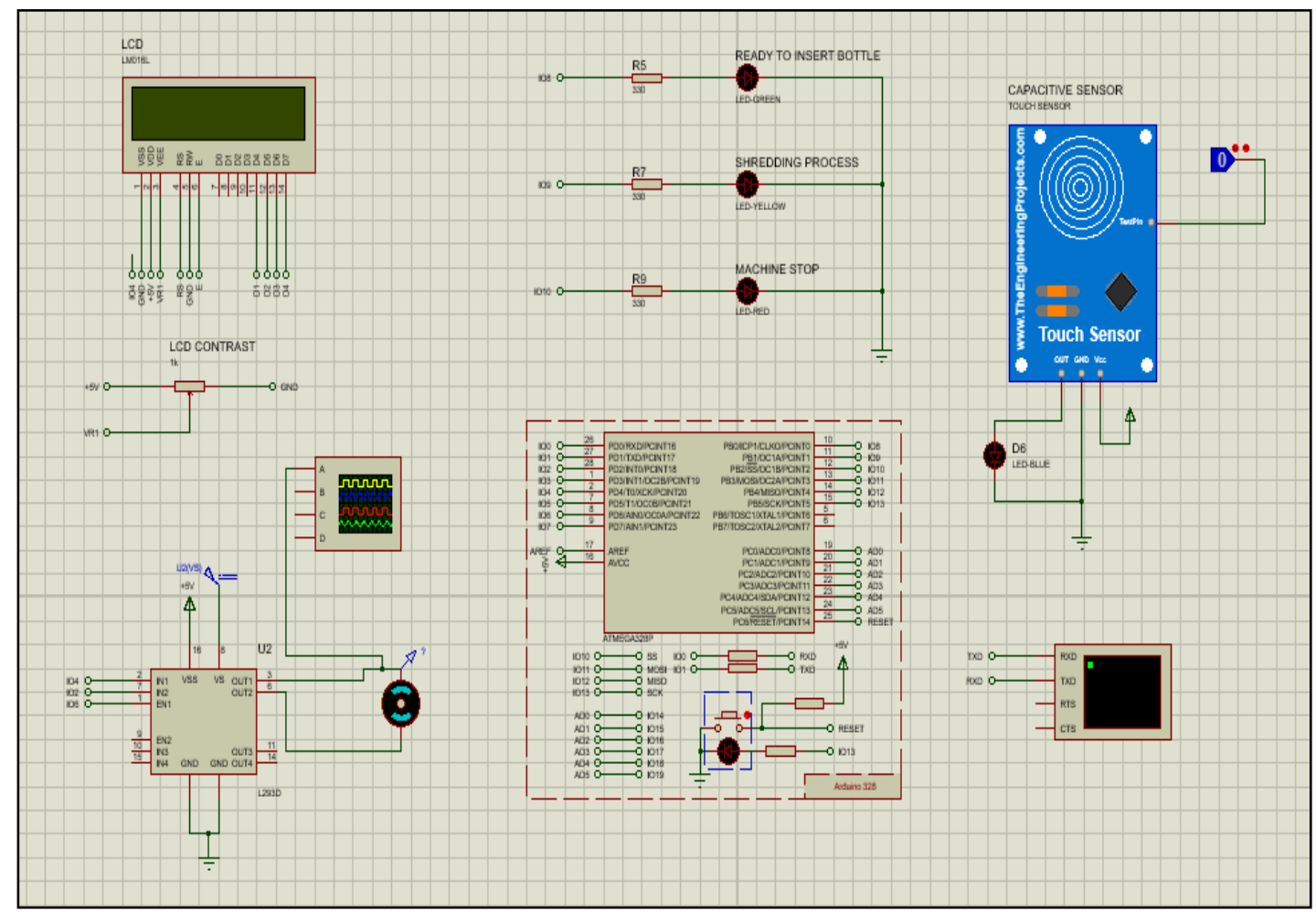

Figure 4 Schematic electrical diagram

\subsection{Product assembly}

The full assembly of shredder unit, coin dispensing unit and final product of PET bottle shredder RVM are shown in Figure 5, 6 and 7. Shredder and motor are connected by using chain drive. Hopper for plastic bottle storage is attached on top of shredder. The receiving of the plastic bottle will be in vertical flow. Beside the receiving area at the top side, there is an LCD to indicate the machine status. The coin dispensing unit is designed at the front side. Electrical control box is designed for the circuit and power supply placement. The reverse vending machine is equipped with 4 caster wheels so that it can be portable. 

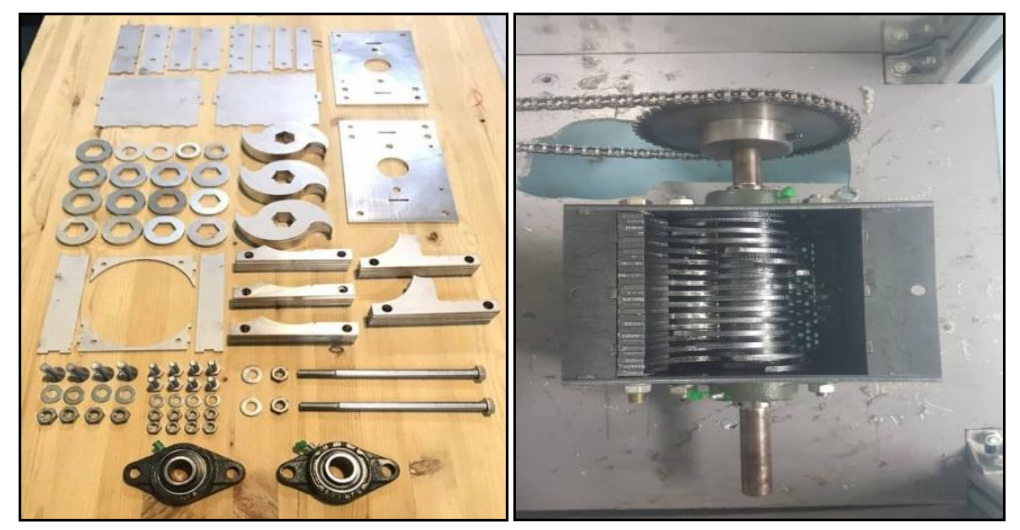

Figure 5 Shredder unit assembly

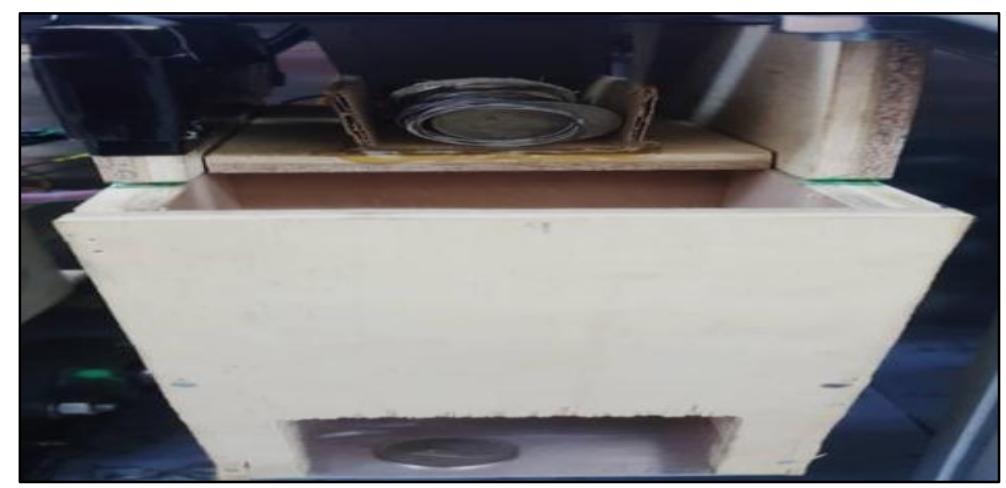

Figure 6 Coin dispensing unit assembly

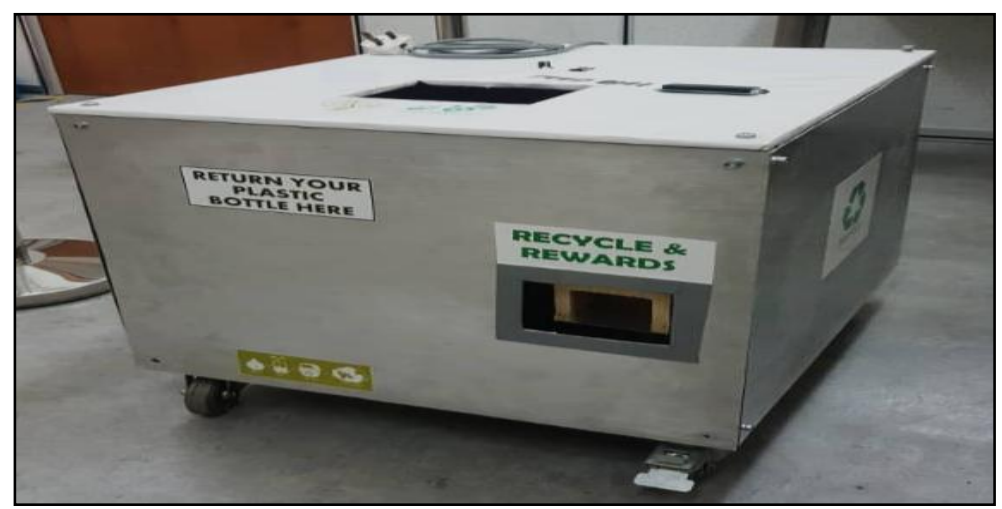

Figure 7 Developed Pet bottle shredder RVM

\section{Results}

A prototype containing all material and component described above has been developed and tested. Several experiments and tests including system interfacing and data analysis were carried out during the development stage to verify the function and well-integrated of each component.

\subsection{Functionality testing of capacitive sensor}

This Reverse Vending Machine uses one capacitive sensor to detect the presence of bottles. Upon detection, the emitting pulse from sensor to the controller will result in incremental number of counters before starting the shredding process. This testing is done to test the capability of the sensor to sense the PET bottle continuously. Based on the Table 1 below, the capacitive sensor has yield about $100 \%$ of detection capability to detect plastic bottles at distance $2 \mathrm{~cm}, 75 \%$ of detection capability at distance $4 \mathrm{~cm}$ and $75 \%$ of detection capability at distance $6 \mathrm{~cm}$. 
Table 1 Detection capability by capacitive sensor

\begin{tabular}{llll}
\hline No of Testing & Material & Distance $(\mathbf{c m})$ & Detection capability \\
\hline 1 & $500 \mathrm{ml}$ PET bottle & 2 & Yes \\
\hline 2 & $500 \mathrm{ml}$ PET bottle & 2 & Yes \\
\hline 3 & $500 \mathrm{ml}$ PET bottle & 4 & Yes \\
\hline 4 & $500 \mathrm{ml}$ PET bottle & 4 & Yes \\
\hline 5 & $500 \mathrm{ml}$ PET bottle & 6 & Nos \\
\hline 6 & $500 \mathrm{ml}$ PET bottle & 6 & Yes \\
\hline 7 & $1000 \mathrm{ml}$ PET bottle & 2 & Yes \\
\hline 8 & $1000 \mathrm{ml}$ PET bottle & 2 & Yes \\
\hline 9 & $1000 \mathrm{ml}$ PET bottle & 4 & No \\
\hline 10 & $1000 \mathrm{ml}$ PET bottle & 4 & Yes \\
\hline 11 & $1000 \mathrm{ml}$ PET bottle & 6 & Yes \\
\hline 12 & $1000 \mathrm{ml}$ PET bottle & 6 & \\
\hline
\end{tabular}

\subsection{Performance result of shredder Unit}

The PET bottle shredder reverse vending machine uses shredder to shred the plastic bottles into small pieces. This testing is conducted to determine whether the shredder can function continuously and able to shred plastic bottles into small pieces. Figure 8 (left) below is plastic pieces of bottle with $0.055 \mathrm{~mm}$ thickness after being shredded and the pieces are thinner and smaller compared to the right that shows plastic pieces of bottle with $0.175 \mathrm{~mm}$ thickness after being shredded. The higher the thickness of the plastic bottle, the thicker and bigger the size of the plastic pieces after being shredded. Table 2 below shows the result of shredding capability and the duration. Two different motors were used in the testing which are $12 \mathrm{~V} \mathrm{Dc}$ and $24 \mathrm{~V}$ Dc motor. Based on the result, the RVM has yield about $67 \%$ of shredding capability by using $12 \mathrm{VDC}$ motor with averagely $19.6 \mathrm{sec}$ for bottle thickness $0.055 \mathrm{~mm}$ and $0.175 \mathrm{~mm}$. By using 24VDC motor, the RVM has yield $90 \%$ capability of shredding with averagely $17.1 \mathrm{sec}$ involving both type of thickness. It can be concluded that the duration of shredding process is proportional to the bottle thickness / bottle type. 24VDC motor has better performance than 12 VDC motor. The Hexagon shaft with curve edge cam shaped cutting knives that are aligned in a "V" shape is proved has the capability as cutting tools.

\begin{tabular}{|c|c|}
\hline Bottle with thickness $0.05 \mathrm{~mm}$ & Bottle with thickness $0.175 \mathrm{~mm}$ \\
\hline & \\
\hline
\end{tabular}

Figure 8 Comparison of shredder PET bottles of two different thickness

Table 2 Performance result of shredding Unit

\begin{tabular}{|c|c|c|c|c|c|}
\hline \multirow[t]{2}{*}{ Motor type } & \multirow[t]{2}{*}{ No of testing } & \multirow{2}{*}{$\begin{array}{l}\text { Bottle } \\
\text { thickness (mm) }\end{array}$} & \multirow{2}{*}{$\begin{array}{l}\text { Shredding duration } \\
\text { (seconds) }\end{array}$} & \multicolumn{2}{|c|}{ Shredding capability } \\
\hline & & & & Pass & Fail \\
\hline \multirow[t]{12}{*}{ 12V Dc Motor } & 1 & 0.055 & 15 & 1 & \\
\hline & 2 & 0.055 & 15 & I & \\
\hline & 3 & 0.055 & 15 & 1 & \\
\hline & 4 & 0.055 & 15 & 1 & \\
\hline & 5 & 0.055 & 15 & 1 & \\
\hline & 6 & 0.055 & 18 & I & \\
\hline & 7 & 0.055 & 18 & 1 & \\
\hline & 8 & 0.055 & 20 & I & \\
\hline & 9 & 0.055 & 23 & & I \\
\hline & 10 & 0.055 & 25 & & I \\
\hline & 11 & 0.175 & 26 & & 1 \\
\hline & 12 & 0.175 & 30 & & I \\
\hline
\end{tabular}


International Journal of Advanced Technology and Engineering Exploration, Vol 8(74)

\begin{tabular}{lllll}
\hline Motor type & No of testing & $\begin{array}{l}\text { Bottle } \\
\text { thickness }(\mathbf{m m})\end{array}$ & $\begin{array}{l}\text { Shredding duration } \\
\text { (seconds) }\end{array}$ & \begin{tabular}{l} 
Shredding capability \\
\cline { 3 - 4 }
\end{tabular} \\
\cline { 2 - 5 } & Average & & 19.6 & Pass \\
\hline 24V Dc Motor & 13 & 0.055 & 12 & $/$ \\
\hline 14 & 0.055 & 12 & $/$ \\
\hline 15 & 0.055 & 12 & $/$ \\
\hline 16 & 0.055 & 15 & $/$ \\
\hline 17 & 0.055 & 15 & $/$ \\
\hline 18 & 0.055 & 18 & $/$ \\
\hline 19 & 0.175 & 20 & $/$ \\
\hline 20 & 0.175 & 20 & $/$ \\
\hline 21 & 0.175 & 22 & 25 \\
\hline 22 & 0.175 & 17.1 & \\
\hline Average & & & $/$ \\
\hline
\end{tabular}

\subsection{Performance result of coin dispenser Unit}

This coin dispenser uses one DC motor connected to a motor driver powered by Arduino Uno. The DC motor is attached to a spring like coil that is made to store coins. The coins are then dispensed by the rotation of motor. This testing is done to test the efficiency of the motor to dispense coin to function continuously and able to dispense the correct number of coins for every 4 bottles counted. Based on the result in Table 3, the coin dispensing unit has yield $75 \%$ capability of dispensing the correct quantity of coin (RM0.20) for every 4 bottles counted with average duration of $2.75 \mathrm{sec}$. It also can be concluded that the capacitive sensor has the $75 \%$ ability to detect the PET bottle. 5V Dc motor is suitable to drive the rotation of spring with load.

Table 3 Performance result of coin dispensing Unit

\begin{tabular}{|c|c|c|c|c|c|c|}
\hline \multirow[t]{2}{*}{ Motor type } & \multirow[t]{2}{*}{ No of testing } & \multirow{2}{*}{$\begin{array}{l}\text { No of bottles } \\
\text { detected }\end{array}$} & \multirow{2}{*}{$\begin{array}{l}\text { Dispensing } \\
\text { (seconds) }\end{array}$} & \multirow[t]{2}{*}{ Duration } & \multicolumn{2}{|c|}{ Dispense Capability } \\
\hline & & & & & Yes & No \\
\hline \multirow[t]{9}{*}{ 5V Dc Motor } & 1 & 4 & 2 & & I & \\
\hline & 2 & 4 & 2 & & I & \\
\hline & 3 & 4 & 3 & & & I \\
\hline & 4 & 3 & 2 & & & I \\
\hline & 5 & 3 & 4 & & & I \\
\hline & 6 & 4 & 2 & & I & \\
\hline & 7 & 4 & 3 & & I & \\
\hline & 8 & 4 & 4 & & I & \\
\hline & Average & & 2.75 & & & \\
\hline
\end{tabular}

\section{Discussion}

\subsection{0verall system performance}

Based on the result, it shows that the capacitive sensor is reliable to detect the plastic bottles inside the hopper. The system manages to detect the plastic bottle every time and the connectivity between sensor and the Arduino controller is established well. The PET bottle shredder RVM is able to shred plastic bottles into small pieces and dispense coins after several testing. Each component has been tested and the PET bottle shredder RVM is able to shred two different thickness of plastic bottles which is mineral water and drinking water plastic bottle. The plastic bottle will turn into small plastic pieces after being shredded for the purpose to be sent to recycles centres. The higher the thickness of the plastic bottle, the thicker and bigger the size of the plastic pieces 31 after being shredded. The duration of shredding process is also proportional to the bottle thickness / bottle type. If this reverse vending machine is implemented in a bigger application scale, the material of the shredder needs to be replaced with stainless steel material so that it can shred tougher PET bottles. In addition, based on the observation from this project that is using a $24 \mathrm{~V}$ Dc electrical motor to drive the shredder unit, it is important to replace the motor with a higher torque motor such as an AC motor to smoothen the shredding process without problems. The conceptual idea of PET Reverse Vending Machine with shredding features is targeted to help collecting, shredding a small quantity of plastic bottles and sending them to recycle centres in form of plastic pieces. This machine can be placed at the nearest and reachable area as one effort to 
promote consumers to recycle plastic bottles. Besides that, the consumers who recycles using this machine will be rewarded in a form of money. This will help cultivate people to start recycling plastic bottle in the future.

\subsection{Limitations}

There are some limitations in operating this prototype RVM; - The label of the PET bottle must be removed before inserting to the hopper as the label sometime will cause the shredder to stuck. Another limitation is the coin storage inside the coin dispenser unit of this prototype is designed to store maximum of 5 coins only. This is due to the main focus of this project which to observe the capability of the dispenser unit to response to the different quantity of inserted bottles before implementing in mass operation.

\section{Conclusion and future work}

Nowadays, the world is at risk by plastic pollutions which is one of the world's biggest environmental threats. Dustbins are overflowed due to these used bottles and mostly goes to landfill to be buried. Plastic is non-biodegradable and takes time to decomposed. In this research work, the PET bottle shredder RVM has been proposed, which employed the combination of two concepts; RVM and shredder machine. Indirectly, it can motivate the public to recycle a small quantity of PET bottle at the nearest and reachable area while gaining the rewards. At the same time, by having the shredding mechanism, this proposed project has reduced one necessary process in the recycle center. The testing results proved that this system is able to receive the bottles, shred and dispense coins accordingly. Future work will focus on the implementation of image processing system to sort out from any other type of material and determine that the inserted bottles are from empty bottle only. Besides, the material of the shredder needs to be further studied so that it can shred variety type of PET bottles.

\section{Acknowledgment}

None.

\section{Conflicts of interest}

The authors have no conflicts of interest to declare.

\section{References}

[1] Degli Antoni G, Marzetti GV. Recycling and waste generation: an estimate of the source reduction effect of recycling programs. Ecological Economics. 2019; 161:321-9.

[2] Tomari R, Zakaria MF, Kadir AA, Wan Zakaria WN, Abd Wahab MH. Empirical framework of reverse vending machine (RVM) with material identification capability to improve recycling. In Applied Mechanics and Materials. 2019; 892:114-9. Trans Tech Publications Ltd.

[3] Moh Y. Solid waste management transformation and future challenges of source separation and recycling practice in Malaysia. Resources, Conservation and Recycling. 2017; 116:1-14.

[4] Chirayil CJ, Mishra RK, Thomas S. Materials recovery, direct reuse and incineration of PET bottles. In recycling of polyethylene terephthalate bottles 2019 (pp. 37-60). William Andrew Publishing.

[5] Chung WK. Waste management in hong kong: feasibility of applying the norwegian deposit return system for plastic bottles (Masters thesis, Norwegian University of Life Sciences). 2019.

[6] Jadhav ND, Patil A, Lokhande H, Turambe D. Development of plastic bottle shredding machine. International Journal of Waste Resources. 2018.

[7] Ayo AW, Olukunle OJ, Adelabu DJ. Development of a waste plastic shredding machine. International Journal of Waste Resources. 2017.

[8] https://lup.lub.lu.se/luur/. Accessed 15 August 2020

[9] https://www.swap-o-matic.com/. Accessed 15 August 2020.

[10] Rudewicz PT, Thomas T, Hopkins MA, Chan RK, inventors; KRh Thermal Systems, assignee. Vending machine including multiple failure control devices. United States Patent US 5,799,822. 1998.

[11] Faiyyaj MI, Pradip MR, Dhanaji BJ, Chandrashekhar DP, Shivaji JS. Design and development of plastic shredding machine. International Journal of Engineering Technology Science and Research. 2017; 4(10):733-7.

[12] Sharma S, Monga A. Implementation of reverse vending machine based on FPGA. International Journal of Emerging Technologies in Computational and Applied Sciences. 2014; 7(3):265-71.

[13] Darshan R, Gururaja S. Design and fabrication of crusher machine for plastic wastes. International Journal of Mechanical and Production Engineering. 2017; 5(10):55-8

[14] Desai SS, Jadhav SM, Patil PS, Sambhaji GN. Automatic chocolate vending machine by using Arduino Uno. International Journal of Innovative Research in Computer Science \& Technology. 2017; 5(2):226-9.

[15] Niu Y, Chu J. The design of beverage vending machines based on PLC. In 4th international conference on information technology and management innovation 2015 (pp. 414-9). Atlantis Press.

[16] Mariya D, Usman J, Mathew EN, PH H, Azeez A. Reverse vending machine for plastic bottle recycling. International Journal of Computer Science Trends and Technology.2020; 8(2):65-70.

[17] Sinaga EF, Irawan R. Developing barcode scan system of a small-scaled reverse vending machine to sorting waste of beverage containers. Telkomnika. 2020; 18(4):2087-94. 


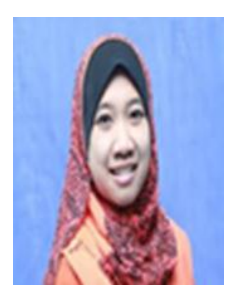

Noor Hasyimah is a Lecturer at UniKL Malaysia France Institute in Selangor, Malaysia. She holds a Master of Science in Telecommunication and Information Engineering from University Teknologi Mara (2010), BEng in Information and Communication from Tokyo Denki University (2006). Her research interests are Automation and Robotics.

Email: noorhasyimah@unikl.edu.my

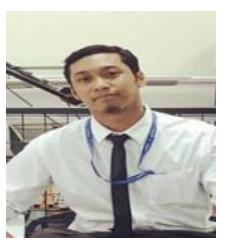

Ahmad Nor Haziq is an undergraduate student at UniKL Malaysia France Institute in Selangor, Malaysia. He is currently studying Bachelor of Engineering Technology in Mechatronics in UniKL

Email: haziq.khatib@s.unikl.edu.my 